\title{
A comprehensive coping strategy programme reduced nausea and fatigue after autologous bone marrow transplantation for breast cancer
}

Gaston-Johansson F Fall-Dickson JM, Nanda J et al. The effectiveness of the comprehensive coping strategy program on clinical outcomes in breast cancer autologous bone marrow transplantation. Cancer Nurs 2000 Aug;23:277-85.

QUESTION: In women having autologous bone marrow transplantation (ABMT) for breast cancer, does a comprehensive coping strategy programme (CCSP) reduce pain, fatigue, psychological distress, and nausea?

\section{Design}

Randomised (unclear allocation concealment*), \{blinded (clinicians, outcome assessors, and statisticians) $\}\}^{*}$, controlled trial with 7 days of follow up after ABMT.

Source of funding: US Department of Defense.

For correspondence: DrF

Gaston-Johansson, International and Extramural Programs, Johns Hopkins

University School of Nursing, 525 North MD 21205-2110,

USA.Fax +1410502 5481 . Wolfe Street, Baltimore,

\section{Setting}

A comprehensive cancer centre in the eastern US.

\section{Patients}

110 women who were $\geqslant 18$ years of age $(53 \%$ were 41-50 y of age); had stage II, III, or IV breast cancer; and were scheduled for ABMT. Follow up was 100\%.

\section{Intervention}

Women were allocated to CCSP $(n=52)$ or no CCSP $(\mathrm{n}=58)$. CCSP consisted of preparatory information to increase control; cognitive restructuring, including posi-

Comprehensive coping strategy programme (CCSP) v no CCSP with autologous bone marrow transplantation for breast cancer

\begin{tabular}{lrrr} 
& \multicolumn{2}{l}{ Mean score } & \\
\cline { 2 - 4 } Outcomes at 7 days & CCSP & No CcSP & $\begin{array}{l}\text { Mean score } \\
\text { difference }(95 \% \mathrm{CI})\end{array}$ \\
Nausea (100 mm VAS) & 19.7 & 32.2 & $12.5(1.5$ to 23.6$)$ \\
\hline Fatigue (100 mm VAS) & 40.9 & 50.4 & $9.5(-0.9$ to 19.8$) \S$ \\
\hline Pain (Gaston-Johansson painometer) & 7.2 & 5.8 & $1.4(-2.0$ to 4.7$) \S$ \\
\hline Anxiety (STAI) & 30.7 & 40.3 & $9.6(5.4$ to 13.9$)$ \\
\hline Depression (BDI) & 10.3 & 12.3 & $2.0(-0.9$ to 4.8$) \S$ \\
\hline
\end{tabular}

$\ddagger \mathrm{BDI}=$ Beck Depression Inventory; STAI = State-Trait Anxiety Inventory; VAS = visual analogue scale. Mean score difference and $\mathrm{Cl}$ calculated from data in article.

Score difference and $\mathrm{Cl}$ calculated from
§Difference is not statistically significant. tive coping statements and avoidance of catastrophising; and relaxation with guided imagery. A clinical social worker taught the CCSP intervention $\geqslant 2$ weeks before hospital admission for chemotherapy and ABMT. The CCSP group received handouts on methods for reducing pain and psychological distress and increasing control, styles of distorted thinking to avoid, 15 positive coping self statements to use, and methods of relaxation therapy using an audiotape.

\section{Main outcome measures}

Pain (Gaston-Johansson Painometer); severity of nausea (100 mm visual analogue scale [VAS]); fatigue (100 mm VAS); and psychological distress (anxiety [State-Trait Anxiety Inventory] and depression [Beck Depression Inventory]).

\section{Main results}

The table shows the unadjusted results. At 7 days, nausea scores were lower in the CCSP group than in the control group $(\mathrm{p}<0.05)$. The CCSP group showed less combined nausea and fatigue than the control group after controlling for demographic variables. Groups did not differ at 7 days for pain or psychological distress.

\section{Conclusion}

In women with breast cancer who had autologous bone marrow transplantation, a comprehensive coping strategy programme reduced nausea and fatigue at 7 days.

*See glossary.

†Information provided by author.

\section{COMMENTARY}

Psycho-oncology is a subdiscipline of oncology that focuses on the psychosocial effects of cancer on patients and their families, explores mediating effects of behavioural variables on cancer risk and disease symptoms, and evaluates the effectiveness of psychological interventions on the course of the disease. ${ }^{1}$ The studies by Gaston-Johansson $e t$ al and Fukui et al belong to the latter category of intervention studies that aim to reduce psychological distress in patients with breast cancer.

Psychological intervention studies for patients with cancer, and especially for women with breast cancer, have been done since the late 1970s. This research culminated in the late 1980s and early 1990s in studies showing not only an improvement in psychological distress but also an increase in survival time ${ }^{2}$ and a reduction in recurrence. ${ }^{3}$ The publication of these papers led to a vast array of studies trying to replicate those findings, some of which also examined variables that might moderate the reported effects on disease course by using immunological and endocrine mechanisms. ${ }^{4}$ Those studies are a result of the confluence of psycho-oncological and psychoneuroimmunological expertise, and they set the standard against which later studies should be judged.

The studies cited above focused mainly on long term outcomes, including survival and recurrence, whereas the studies by Fukui et al and Gaston-Johansson et al investigate short term effects on measures of psychological distress only. Although the results of both studies support previous findings, the short term effects are smaller than those reported earlier. ${ }^{5}$ This may be due to several methodological aspects. The patients in both studies represent a highly selected sample with minor affective disturbances as measured by baseline scores of depression and anxiety. Thus, further improvements may be hard to achieve with these outcome measures. In such studies it may be more appropriate to include measures of quality of life (QoL). Both studies claim that the intervention enhanced the QoL of the patients but neither study measured this construct directly. Numerous scales are available for an estimation of QoL, especially scales for patients with cancer. ${ }^{6}$ Furthermore, Gaston-Johansson et al used the Beck Depression Inventory, among other scales, which is an instrument designed for measuring depression in psychiatric patients. Therefore, a floor effect exists and little variance could be expected for this measure. The use of breast cancer specific measures is advised for future research. 


\section{A psychosocial group intervention reduced psychological distress and enhanced coping in primary breast cancer}

Fukui S, Kugaya A, Okamura H, et al. A psychosocial group intervention for Japanese women with primary breast carcinoma. A randomized controlled trial. Cancer 2000 Sep 1;89:1026-36.

QUESTION: In women with primary breast carcinoma and a high risk of recurrence, does a psychosocial group intervention reduce psychological distress and enhance coping?

\section{Design}

Randomised \{allocation concealed*\}†, unblinded*, controlled trial with 6 months of follow up.

\section{Setting}

A cancer centre in Japan.

\section{Patients}

50 women who were $<65$ years of age (mean age $53 \mathrm{y}$ ), were at high risk of recurrence (ie, axillary lymph node metastasis and/or histological or nuclear grade 2-3), had surgery within the previous 4-18 months, and had completed chemotherapy if it was part of their treatment regimen. Exclusion criteria were severe mental disorders, dementia, major depression, or cancer at another site. Follow up was $100 \%$ at 6 weeks and $92 \%$ at 6 months.

\section{Intervention}

Women were allocated to a psychosocial group intervention $(n=25)$ or a waiting list control group $(n=25)$. The intervention group met weekly for 1.5 hours in groups of 6-10 women for 6 weeks. The sessions consisted of (1) health education (including handouts and reading materials); (2) coping skills training, which included scenarios of effective and ineffective coping for 8 common problems/situations; (3) stress management, which included relaxation exercises; and (4) psychosocial support. The same 2 therapists (a psychiatrist and a clinical psychologist) led each intervention group.

\section{Main outcome measures}

Psychological distress (Profile of Mood States, 65 item self rating scale); coping with having cancer (Mental Adjustment to Cancer [MAC] scale, 5 subscales [fighting spirit, anxious preoccupation, fatalism, helplessness/ hopelessness, and avoidance]); and clinical anxiety and depression (Hospital Anxiety and Depression Scale, 14 item self rating scale).

\section{Main results}

The intervention group showed less psychological distress than the control group at 6 weeks $(\mathrm{p}=0.01)$ and 6 months $(p=0.009)$ (table). The intervention and control groups differed on 1 of the 5 subscales of the MAC: higher fighting spirit scores at 6 weeks $(p=0.003)$ (table) and a trend towards higher fighting spirit scores $(\mathrm{p}=0.07)$ at 6 months were seen in the intervention group. The groups did not differ for anxiety and depression levels.

\section{Conclusion}

In women with primary breast carcinoma, a psychosocial group intervention reduced psychological distress.

*See glossary. $\dagger$ Information provided by author.
Sources of funding: Japanese Ministry of Health and Welfare and the Fumiko Yamaji Trust for Academic Nursing Education and Research, Japan.

For correspondence: Dr Y Uchitomi, Psycho-Oncology Division, National Cancer Center Research Institute East, 6-5-1 Kashiwanoha, Kashiwa, Chiba, 277-8577, Japan. Fax +81471347026.
A psychosocial group intervention v waiting list control for primary breast cancer $\ddagger$

\begin{tabular}{|c|c|c|c|}
\hline \multirow[b]{2}{*}{ Outcomes } & \multicolumn{2}{|l|}{ Mean score } & \multirow{2}{*}{$\begin{array}{l}\text { Mean score difference } \\
(95 \% \mathrm{CI} \text { ) (all differences } \\
\text { favour the intervention } \\
\text { group) }\end{array}$} \\
\hline & $\begin{array}{l}\text { Psychosocial } \\
\text { intervention }\end{array}$ & Control & \\
\hline $\begin{array}{l}\text { Psychological distress (POMS) } \\
\text { at } 6 \text { weeks }\end{array}$ & 12.7 & 25.1 & $12.4(10.5$ to 14.3$)$ \\
\hline $\begin{array}{l}\text { Psychological distress (POMS) } \\
\text { at } 6 \text { months }\end{array}$ & 13.3 & 25.1 & $11.8(10.0$ to 13.6$)$ \\
\hline $\begin{array}{l}\text { Fighting spirit (MAC subscale) at } \\
6 \text { weeks }\end{array}$ & 53.3 & 49.4 & 3.9 (3.4 to 4.4$)$ \\
\hline
\end{tabular}

\section{COMMENTARY_continued from previous page}

Both studies used multimodal intervention programmes, arguing that the diagnosis and treatment of cancer cause multidimensional psychosocial problems that are best addressed by multimodal programmes. Another review suggests that strictly focused approaches should be tested to determine the most effective one. ${ }^{5}$ This strategy could lead to interventions that are briefer and more economical and that help to identify the mechanisms responsible for the therapeutic effect. When applying such multimodal interventions, helpful and ineffective components are hard to differentiate from one another. Furthermore, the independent use of the programme's components and unspecific mutual support outside the sessions have not been assessed in the current studies.

In summary, these studies provide further evidence that psychosocial interventions result in statistically significant improvements in mood or coping in patients with cancer. When discussing the generalisability of findings from intervention studies in psycho-oncology, however, the clinical relevance of results is a crucial point. Although some effects may be statistically significant, clinically relevant improvements may not be given. Thus, defining the clinically relevant endpoints in these trials is important. This can be achieved by using long term follow up assessments of survival time or disease free intervals. On the other hand, when using interventions that focus on psychosocial outcomes, measures should be chosen that are specific and responsive.

Karl-Heinz Schulz, MD, PhD

University Hospital Eppendorf Hamburg, Germany

1 Holland JC, editor. Psycho-oncology. New York: Oxford University Press, 1998:717-27.

Spiegel D, Bloom JR, Kraemer HC, et al. Effect of psychosocial treatment on survival of patients with metastatic breast cancer. Lancet 1989;2:888-91.

3 Fawzy FI, Fawzy NW, Hyun CS, et al. Malignant melanoma. Effects of an early structured psychiatric intervention, coping, and affective state on recurrence and survival 6 years later. Arch Gen Psychiatry 1993;50:681-9.

4 Spiegel D, Sephton SE, Terr AI, et al. Effects of psychosocial treatment in prolonging cancer survival may be mediated by neuroimmune pathways. Ann N Y Acad Sci 1998;840:674-83.

5 Jacobson PB, Hann DM. Cognitive-behavioral interventions. In: Holland JC, editor. Psycho-oncology. New York: Oxford University Press, 1998;717-27.

6 Cella D. Quality of life. In: Holland JC, editor. Psycho-oncology. New York: Oxford University Press, 1998:1135-46. 